\title{
Stability of Edible Oils Containing Triacylglycerol and Diacyl- glycerol in the Presence of Tocopherol and/or Vitamin C
}

\author{
Yoshimi OHNo* \\ Department of Food Science and Nutrition, School of Human Environmental Sciences, Mukogawa Women's University \\ (6-46 Ikebiraki, Nishinomiya, Hyogo 663-8558, JAPAN)
}

Edited by K. Takahata, Okayama Univ., and accepted December 3, 2004 (received for review June 14, 2004)

\begin{abstract}
Autoxidation of triacylglycerol (TG) oil occurred most rapidly, whereas oils containing tocopherol (Toc) showed a slower increase compared to the ordinary TG oil. Autoxidation of oils was apparently delayed by addition of Toc and vitamin C (VC), and the effect of these antioxidants was greater in diacylglycerol (DG) oil than in TG oil. On the other hand, there was no apparent difference between DG and TG oils in the presence of Toc only. The $\Delta \mathrm{E}$ values (color difference) of TG oils were higher than those of $\mathrm{DG}$ oils, and the values were lower in the oils containing both Toc and VC than in those containing only Toc. The carbonyl value (COV) of TG oil increased with aeration time and tended to be lower without Toc than with Toc. The peroxide value (POV) of DG oil did not change with aeration time, whereas POV of TG oil increased with aeration time and the amount of Toc. COV and the $p$-anisidin value (ANV) increased with the number of uses, however, the values of DG oils containing Toc tended to be lower than those of the other samples. The dehydration rate, weight decrease and moisture content tended to decrease with the number of uses, which might contribute to the oily or greasy taste of fried food. COV, ANV and the acid value (AV) showed significant correlation with each other, but not with oil absorption, dehydration rate, weight decrease or moisture content.
\end{abstract}

Key words: edible oil, triacylglycerol, diacylglycerol, oxidative stability, tocopherol, vitamin $\mathrm{C}$

\section{Introduction}

Recently, there has been increasing interest in the beneficial effects on lipid metabolism of diacylglycerol (DG) consisting of the 1,3-DG and 1,2-DG species. In rats and humans, consumption of DG reduces total body fat accumulation to a greater extent than that of triacylglycerol (TG) (1-4). DG also lowers serum TG concentrations in rats and humans $(5,6)$. The Healthy Econa brand of oil (DG oil, Kao Co., Tokyo) is about $80 \%$ DG, of which $65-70 \%$ is in the 1,3-DG form. Autoxidation of DG oil at $50^{\circ} \mathrm{C}$ is much slower than that of ordinary TG-based oil (TG oil) (7). One of the reasons for the stability of DG oil is the addition of tocopherol (Toc) and vitamin $\mathrm{C}(\mathrm{VC})$ as antioxidants. The differences in their structures may affect the stability of the lipids. Therefore, the aim of the present study is to determine the effects of Toc and VC addition on the stability of edible oils.

\section{Experimental}

\subsection{Materials}

Edible oils (TG-H) and TG oils containing Toc were provided by Honen Co., Tokyo. Toc contents of TG oils were adjusted at approximately the same (TG-1) and approximately half (TG-2) of the levels of DG oil (DG1). The fatty acid compositions of the sample oils and

\footnotetext{
${ }^{*}$ Correspondence to: Yoshimi OHNO, Department of Food Science and Nutrition, School of Human Environmental Sciences, Mukogawa Women's University, 6-46 Ikebiraki, Nishinomiya, Hyogo 663-8558, JAPAN

E-mail: yiohno@mwu.mukogawa-u.ac.jp
} 
the amounts of Toc are shown in Table 1. The composition of the other sample oils, which were provided by Nissin Oillio Co., Tokyo, are shown in Table 2. The fatty acid compositions and Toc contents of TG (TGToc, TG-Toc/VC) and DG oils (DG-Toc) were adjusted at approximately the same levels as those of DG oil (DG-2).

\section{$2 \cdot 2$ Autoxidation}

About one gram of the sample oil in a Petri dish (4.0 $\mathrm{cm}$ i.d. $\times 1.5 \mathrm{~cm}$ depth) was kept in an incubator at $50^{\circ} \mathrm{C}$ for the indicated periods. The degree of autoxidation was determined by measuring the increase in weight. A similar experiment was carried out in the dark at $40^{\circ} \mathrm{C}$ for over four months.

\section{$2 \cdot 3$ Oxidation at $40{ }^{\circ} \mathrm{C}$ by Aeration under Fluorescent Lamp}

A total of $200.0 \mathrm{~g}$ of the sample oil was put in a 500

Table 1 Fatty Acid and Tocopherol Compositions of Various Sample Oils.

\begin{tabular}{|c|c|c|c|c|}
\hline Sample oil & TG-1 & TG-2 & TG-H & DG-1 \\
\hline \multicolumn{5}{|c|}{ Fatty acid composition (\%) } \\
\hline $\mathrm{C} 16: 0$ & & 6.0 & & 3.3 \\
\hline $\mathrm{C} 16: 1$ & & 0.3 & & 0.2 \\
\hline $\mathrm{C} 18: 0$ & & 2.3 & & 1.1 \\
\hline $\mathrm{C} 18: 1$ & & 52.8 & & 39.1 \\
\hline $\mathrm{C} 18: 2$ & & 28.8 & & 47.6 \\
\hline $\mathrm{C} 18: 3$ & & 7.8 & & 8.0 \\
\hline $\mathrm{C} 20: 0$ & & 0.6 & & 0.2 \\
\hline $\mathrm{C} 20: 1$ & & 1.1 & & 0.5 \\
\hline $\mathrm{C} 22: 1$ & & 0.3 & & - \\
\hline \multicolumn{5}{|c|}{ Tocopherol (Toc) (ppm) } \\
\hline$\alpha$-Toc & 277 & 220 & 182 & 235 \\
\hline$\beta$-Тос & 18 & 11 & 4 & 25 \\
\hline$\gamma$-Toc & 1358 & 847 & 463 & 1269 \\
\hline$\delta$-Тoc & 381 & 192 & 37 & 461 \\
\hline Total Toc & 2034 & 1270 & 686 & 1990 \\
\hline
\end{tabular}

The tocopherol (Toc) contents of TG oils provided by Honen Co. were adjusted at approximately the same (TG-1) and approximately half (TG-2) of the levels of DG oil (DG-1, Healthy Econa brand oil, Kao Co.). TG-H was TG-based oil and not adjusted the tocopherol level. $\mathrm{ml}$ glass flask and capped with a silicon cap (air supply, $200 \sim 300 \mathrm{ml} / \mathrm{min}$ ). The flask was shaken reciprocally at the rate of $100 \sim 115$ times/min under fluorescent lamp (daytime, 570 575 Lux; night-time, 460 520 Lux) at $40^{\circ} \mathrm{C}$.

Table 2 Fatty Acid and Tocopherol Compositions and Vitamin C Contents of Various Sample Oils.

\begin{tabular}{|c|c|c|c|c|}
\hline & TG-Toc & TG-Toc/VC & DG-Toc & DG-2 \\
\hline \multicolumn{5}{|l|}{ Acylglycerols (\%) } \\
\hline MG & & 0.2 & 5.2 & 2.8 \\
\hline DG & & 0.8 & 93.3 & 83.5 \\
\hline TG & & 99.0 & 1.5 & 13.7 \\
\hline \multicolumn{5}{|l|}{ Fatty acid } \\
\hline \multicolumn{5}{|l|}{ composition $(\%)$} \\
\hline $\mathrm{C} 14: 0$ & & 0.0 & 0.1 & 0.0 \\
\hline $\mathrm{C} 16: 0$ & & 8.7 & 11.4 & 3.1 \\
\hline $\mathrm{C} 16: 1$ & & 0.1 & 0.2 & 0.1 \\
\hline $\mathrm{C} 18: 0$ & & 3.2 & 2.9 & 1.3 \\
\hline $\mathrm{C} 18: 1$ & & 38.2 & 37.2 & 39.4 \\
\hline $\mathrm{C} 18: 2$ & & 40.6 & 39.8 & 46.9 \\
\hline $\mathrm{C} 18: 3$ & & 7.5 & 7.2 & 7.9 \\
\hline $\mathrm{C} 20: 0$ & & 0.5 & 0.3 & 0.3 \\
\hline $\mathrm{C} 20: 1$ & & 0.6 & 0.4 & 0.6 \\
\hline $\mathrm{C} 22: 0$ & & 0.4 & 0.3 & 0.2 \\
\hline $\mathrm{C} 22: 1$ & & 0.0 & 0.0 & 0.1 \\
\hline $\mathrm{C} 24: 0$ & & 0.2 & 0.1 & 0.1 \\
\hline $\mathrm{C} 24: 1$ & & 0.0 & 0.1 & 0.0 \\
\hline \multicolumn{5}{|l|}{ Tocopherol (Toc) (ppm) } \\
\hline$\alpha$-Тoc & & 330 & 317 & 250 \\
\hline$\beta$-Тос & & 29 & 20 & 28 \\
\hline$\gamma$-Toc & & 1232 & 1126 & 1176 \\
\hline$\delta$-Тoc & & 359 & 327 & 386 \\
\hline Total Toc & & 1950 & 1790 & 1840 \\
\hline Vitamin C esters (ppm) & - & 250 & - & 250 \\
\hline
\end{tabular}

Sample oils (TG-Toc, TG-Toc/VC and DG-Toc) provided by Nissin Oilio Co. Sample oils were adjusted at approximately the same level of fatty acid and tocopherol compositions of DG oil (DG-2, Healthy Econa brand oil, Kao Co.).

MG; monoacylglycerol, DG; diacylglycerol, TG; triacylglycerol. 


\section{$\mathbf{2} \cdot 4$ Thermal Stability of Oil}

Approximately $60 \mathrm{~g}$ of French fried potato (crinkle, $12 \mathrm{~mm}$, McCain Foods Ltd., Canada) was fried in each sample oils (approx. $600 \mathrm{~g}$ ) for $3 \mathrm{~min}$ at $180^{\circ} \mathrm{C}$ using a fryer (NF-F150, Matsushita Electric Ind. Co., Osaka). The frying procedure was repeated 15 times at more than two-hour intervals and was carried out for three days.

The rates of oil absorption to and dehydration from the food were calculated by subtracting the amount of oil or materials after frying from that before frying. The color difference ( $\Delta \mathrm{E}$ value) in the sample oils was determined by a color meter (ZE-2000, Nippon Denshoku Ind. Co., Tokyo).

\subsection{Chemical Properties of Oil}

The acid value (AV) (8), the peroxide value (POV) (9) and the $p$-anisidin value (ANV) (10) in the sample oils were determined by standard methods for the analysis of fats and oils specified by the Japan Oil Chemists' Society. The carbonyl value (COV) was determined according to the method of Chiba et al. (11).

\subsection{Statistical Analysis}

Statistical analysis was carried out using Stat View software (Version 5.0, SAS Institute Inc., NC, USA). Pearson's correlation coefficients were used for examining the relationships among the parameters examined.

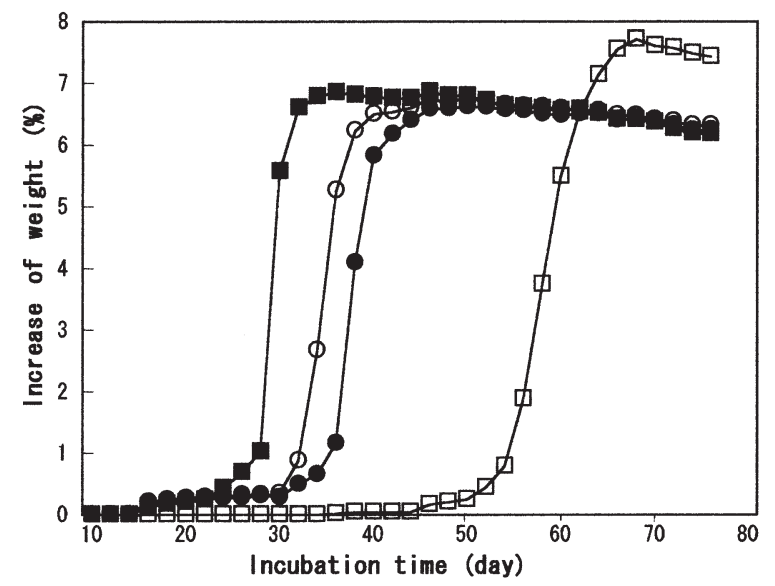

Fig. 1 Autoxidation of Sample Oils Listed in Table 1 by Weighing Method at $50^{\circ} \mathrm{C}$.

○, TG-1; $\bigcirc$, TG-2; $\square$, TG-H; $\square$, DG-1.

\section{Results}

\section{$3 \cdot 1$ Autoxidation of Sample Oils}

Figure 1 shows the degree of autoxidation of TGH,TG oils containing Toc (TG-1 and TG-2) and DG-1 at $50^{\circ} \mathrm{C}$. The weight increase of TG-H occurred rapidly after three weeks, whereas TG-1 and TG- 2 showed a slow increase according to the amount of Toc. On the other hand, autoxidation of DG-1 occurred after two months. The lag phase of autoxidation was prolonged under dark conditions.

Figure 2 shows the degree of autoxidation of the sample oils listed in Table 2. TG-based oil (TG-N) without Toc and $\mathrm{VC}$ was used in the similar experiment for comparison. There was an apparent difference in autoxidation among the sample oils. TG-N was oxidized most rapidly, whereas oxidation of DG-2 was apparently delayed. TG-Toc and DG-Toc had almost at the same levels of autoxidation, whereas the level of autoxidation of TG-Toc/VC was between those of TG$\mathrm{N}$ and DG-2 (Fig. 2).

\section{$3 \cdot 2$ Oxidation at $40{ }^{\circ} \mathrm{C}$ by Aeration under Fluorescent Lamp}

Table 3 shows the $\Delta \mathrm{E}$ value of the sample oils listed in Table 1. The $\Delta \mathrm{E}$ values of TG oils were higher than that of DG-1 and increased when Toc was added. As shown in Table 4, the $\Delta \mathrm{E}$ values of TG oils were higher than those of DG oils, and the $\Delta \mathrm{E}$ values were lower for

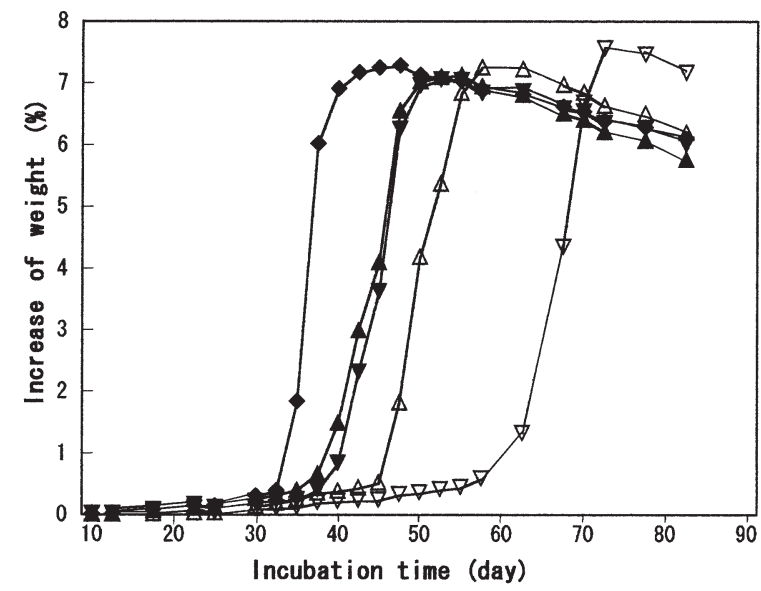

Fig. 2 Autoxidation of Sample Oils Listed in Table 2 by Weighing Method at $50^{\circ} \mathrm{C}$.

$\boldsymbol{\Delta}$, TG-Toc; $\triangle$, TG-Toc/VC; $\boldsymbol{\nabla}$, TG-N; $\boldsymbol{\nabla}$, DGToc; $\nabla, \mathrm{DG}-2$ (DG-Toc/VC). 
the oils containing both Toc and VC than for those containing only Toc.

Figure 3 shows COV, POV and AV of the sample oils listed in Table 1. COV of DG-1 increased very

Table 3 Changes in Colors of Sample Oils listed in Table 1 during Oxidation under Fluorescent Lamp at $40^{\circ} \mathrm{C}$.

\begin{tabular}{|c|c|c|c|c|c|}
\hline \multicolumn{2}{|c|}{ Incubation time (day) } & \multirow{2}{*}{$\begin{array}{r}\text { L value } \\
96.77\end{array}$} & \multirow{2}{*}{$\frac{\text { a value }}{-2.43}$} & \multirow{2}{*}{$\begin{array}{r}\text { b value } \\
7.70\end{array}$} & \multirow{2}{*}{$\frac{\Delta \mathrm{E} \text { value }}{0.00}$} \\
\hline TG-1 : & 0 & & & & \\
\hline & 7 & 93.39 & -2.93 & 9.56 & 1.96 \\
\hline & 10 & 96.57 & -2.94 & 9.71 & 2.08 \\
\hline & 13 & 96.56 & -2.85 & 9.68 & 2.04 \\
\hline & 16 & 96.46 & -2.78 & 9.72 & 2.07 \\
\hline & 19 & 96.38 & -2.70 & 9.82 & 2.17 \\
\hline & 22 & 96.33 & -2.69 & 9.95 & 2.24 \\
\hline & 25 & 96.21 & -2.67 & 10.22 & 2.58 \\
\hline & 28 & 96.19 & -2.69 & 10.52 & 2.89 \\
\hline & 31 & 96.48 & -2.79 & 10.92 & 3.25 \\
\hline \multirow[t]{10}{*}{ TG-2 : } & 0 & 96.29 & -2.26 & 7.68 & 0.00 \\
\hline & 7 & 96.11 & -2.65 & 9.49 & 1.86 \\
\hline & 10 & 96.07 & -2.60 & 9.50 & 1.87 \\
\hline & 13 & 96.02 & -2.55 & 9.45 & 1.81 \\
\hline & 16 & 96.16 & -2.52 & 9.44 & 1.78 \\
\hline & 19 & 95.94 & -2.42 & 9.47 & 1.83 \\
\hline & 22 & 95.89 & -2.37 & 9.61 & 1.98 \\
\hline & 25 & 95.94 & -2.37 & 9.74 & 2.09 \\
\hline & 28 & 95.90 & -2.34 & 10.01 & 2.37 \\
\hline & 31 & 96.12 & -2.37 & 10.30 & 2.63 \\
\hline \multirow[t]{10}{*}{ TG-H： } & 0 & 95.98 & -2.33 & 7.59 & 0.00 \\
\hline & 7 & 96.41 & -2.78 & 9.19 & 1.71 \\
\hline & 10 & 96.37 & -2.71 & 9.19 & 1.69 \\
\hline & 13 & 96.24 & -2.77 & 9.16 & 1.64 \\
\hline & 16 & 96.25 & -2.72 & 9.11 & 1.59 \\
\hline & 19 & 96.31 & -2.64 & 9.07 & 1.55 \\
\hline & 22 & 95.65 & -2.54 & 9.32 & 1.77 \\
\hline & 25 & 95.54 & -2.51 & 9.40 & 1.87 \\
\hline & 28 & 95.56 & -2.54 & 9.52 & 1.99 \\
\hline & 31 & 95.69 & -2.49 & 9.74 & 2.18 \\
\hline \multirow[t]{10}{*}{ DG-1 : } & 0 & 96.39 & -1.56 & 5.59 & 0.00 \\
\hline & 7 & 96.47 & -1.58 & 5.86 & 0.28 \\
\hline & 10 & 96.47 & -1.60 & 5.94 & 0.36 \\
\hline & 13 & 96.42 & -1.60 & 6.04 & 0.46 \\
\hline & 16 & 96.28 & -1.60 & 6.19 & 0.61 \\
\hline & 19 & 95.93 & -1.58 & 6.42 & 0.95 \\
\hline & 22 & 95.88 & -1.62 & 6.54 & 1.08 \\
\hline & 25 & 95.93 & -1.64 & 6.56 & 1.07 \\
\hline & 28 & 96.40 & -1.69 & 6.55 & 0.97 \\
\hline & 31 & 96.02 & -1.70 & 6.92 & 1.39 \\
\hline
\end{tabular}

slightly after aeration for 31 days. COV of TG oils increased with aeration time, and this increase tended to be less for TG oils without Toc (TG-H) than for those with Toc (TG-1 and TG-2). The amount of Toc did not

Table 4 Changes in Colors of Sample Oils listed in Table 2 during Oxidation under Fluorescent Lamp at $40^{\circ} \mathrm{C}$.

\begin{tabular}{|c|c|c|c|c|c|}
\hline \multicolumn{2}{|c|}{ Incubation time (day) } & \multirow{2}{*}{$\begin{array}{r}\text { L value } \\
96.77\end{array}$} & \multirow{2}{*}{$\frac{\text { a value }}{-1.80}$} & \multirow{2}{*}{$\frac{\mathrm{b} \text { value }}{5.55}$} & \multirow{2}{*}{$\frac{\Delta \mathrm{E} \text { value }}{0.00}$} \\
\hline TG-Toc : & 0 & & & & \\
\hline & 7 & 93.39 & -2.47 & 8.06 & 2.62 \\
\hline & 10 & 96.25 & -2.77 & 9.36 & 3.96 \\
\hline & 13 & 96.15 & -2.87 & 9.85 & 4.47 \\
\hline & 16 & 96.11 & -2.80 & 9.85 & 4.46 \\
\hline & 19 & 96.20 & -2.77 & 9.82 & 4.41 \\
\hline & 22 & 96.14 & -2.72 & 9.81 & 4.40 \\
\hline & 25 & 96.09 & -2.69 & 9.91 & 4.50 \\
\hline & 28 & 96.07 & -2.66 & 10.02 & 4.60 \\
\hline & 31 & 96.08 & -2.63 & 10.22 & 4.79 \\
\hline \multirow[t]{10}{*}{ TG-Toc/VC : } & 0 & 93.81 & -1.48 & 6.57 & 0.00 \\
\hline & 7 & 96.45 & -2.19 & 7.62 & 2.79 \\
\hline & 10 & 96.40 & -2.41 & 7.81 & 3.01 \\
\hline & 13 & 96.36 & -2.56 & 8.48 & 3.36 \\
\hline & 16 & 96.20 & -2.74 & 9.37 & 3.89 \\
\hline & 19 & 96.22 & -2.74 & 10.09 & 4.11 \\
\hline & 22 & 95.86 & -2.72 & 9.80 & 4.02 \\
\hline & 25 & 95.85 & -2.69 & 9.89 & 4.08 \\
\hline & 28 & 95.84 & -2.68 & 9.93 & 4.10 \\
\hline & 31 & 95.76 & -2.59 & 10.06 & 4.15 \\
\hline \multirow[t]{10}{*}{ DG-Toc： } & 0 & 96.70 & -1.60 & 7.36 & 0.00 \\
\hline & 7 & 95.23 & -1.38 & 7.36 & 0.82 \\
\hline & 10 & 95.14 & -1.28 & 7.33 & 0.94 \\
\hline & 13 & 95.50 & -1.28 & 7.37 & 0.63 \\
\hline & 16 & 95.34 & -1.26 & 7.51 & 0.72 \\
\hline & 19 & 94.93 & -1.17 & 7.78 & 1.12 \\
\hline & 22 & 94.59 & -1.15 & 7.92 & 1.47 \\
\hline & 25 & 95.29 & -1.15 & 8.13 & 0.93 \\
\hline & 28 & 95.12 & -1.15 & 8.54 & 1.30 \\
\hline & 31 & 94.62 & -1.21 & 9.14 & 2.03 \\
\hline \multirow[t]{10}{*}{ DG-2 : } & 0 & 96.70 & -1.53 & 5.07 & 0.00 \\
\hline & 7 & 96.70 & -1.51 & 5.12 & 0.06 \\
\hline & 10 & 96.65 & -1.47 & 5.15 & 0.12 \\
\hline & 13 & 96.65 & -1.45 & 5.25 & 0.21 \\
\hline & 16 & 96.61 & -1.49 & 5.39 & 0.34 \\
\hline & 19 & 96.61 & -1.50 & 5.43 & 0.38 \\
\hline & 22 & 96.55 & -1.54 & 5.55 & 0.51 \\
\hline & 25 & 96.57 & -1.56 & 5.66 & 0.61 \\
\hline & 28 & 96.34 & -1.54 & 5.81 & 0.83 \\
\hline & 31 & 96.02 & -1.48 & 5.94 & 1.11 \\
\hline
\end{tabular}



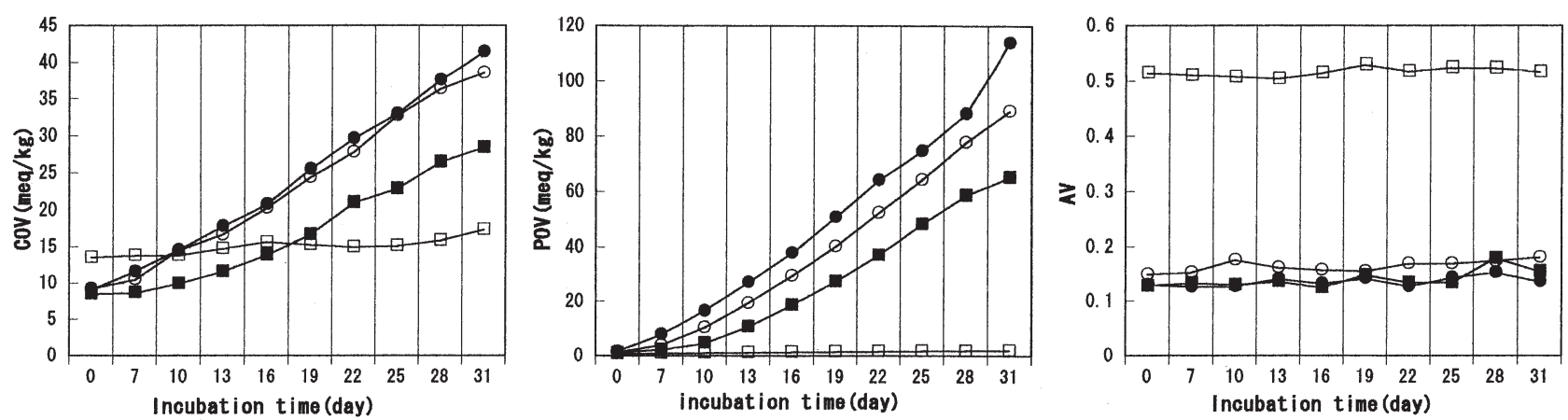

Fig. 3 Changes in Carbonyl (COV), Peroxide (POV) and Acid Values (AV) of Sample Oils listed in Table 1 by Aeration under Fluorescent Lamp.

Left, COV; Middle, POV; Right, AV. ○, TG-1; ○, TG-2; $\mathbf{\square}$, TG-H; $\square$, DG-1.

influence the increase in COV. On the other hand, the POV of DG-1 did not change, whereas POV of TG oil increased with both aeration time and the amount of Toc as same as shown in COV. AV of fresh DG oil was higher than that of TG oil, although AV values of both TG and DG oils did not increase by aeration.

Figure 4 shows $\mathrm{COV}, \mathrm{POV}$ and $\mathrm{AV}$ of the sample oils listed in Table 2. COV and POV of DG-2 did not change during the experimental period, whereas those values of TG-Toc /VC increased gradually after aeration for 19 days. DG-Toc showed increases in both $\mathrm{COV}$ and POV, and the values were higher than those of the other sample oils up to 22 days of aeration. COV and POV of TG-Toc increased rapidly after aeration for 13 days. The AV of all sample oils showed no increase during the experimental period.

\section{$3 \cdot 3 \quad$ Thermal Stability of Oil}

The average percentages of oil absorption, dehydration rate, weight decrease and moisture content of all sample oils listed in Tables $\mathbf{1}$ and $\mathbf{2}$ were $5.8 \pm 1.3 \%$, $36.5 \pm 1.6 \%, 30.7 \pm 1.4 \%$ and $53.6 \pm 2.5 \%$, respectively, after 15 times frying.

Figure 5 shows the $\Delta \mathrm{E}$ values of the sample oils listed in Table 2. The $\Delta \mathrm{E}$ values of DG-2 showed the highest value among the sample oils, and the amount of Toc did not seem to influence the values of the sample oils after these were used 12 times for frying. TG-Toc/VC showed the lowest $\Delta \mathrm{E}$ value. The $\Delta \mathrm{E}$ values of $\mathrm{TG}-\mathrm{H}$, TG-1 and TG-2 increased with the number of uses and no difference was observed among the sample oils (data not shown).

Figure 6 shows COV, ANV and AV of the sample oils listed in Table 1. COV and ANV increased with the
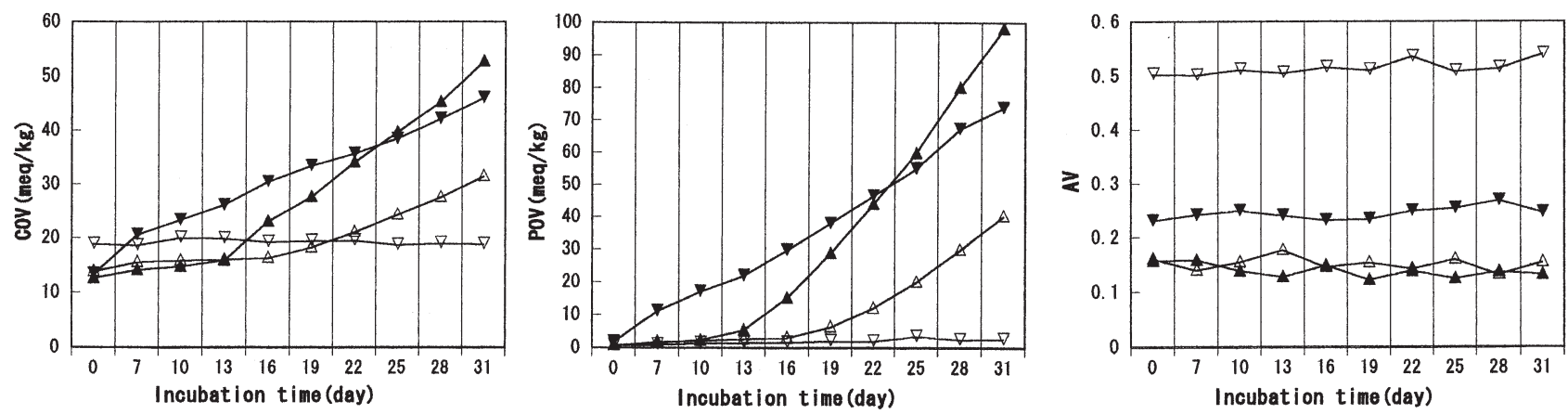

Fig. 4 Changes in Carbonyl (COV), Peroxide (POV) and Acid Values (AV) of Sample Oils listed in Table 2 by Aeration under Fluorescent Lamp.

Left, COV; Middle, POV; Right, AV.

$\Delta$, TG-Toc; $\triangle$, TG-Toc/VC; $\boldsymbol{\nabla}$, DG-Toc; $\nabla$, DG-2 (DG-Toc/VC) . 


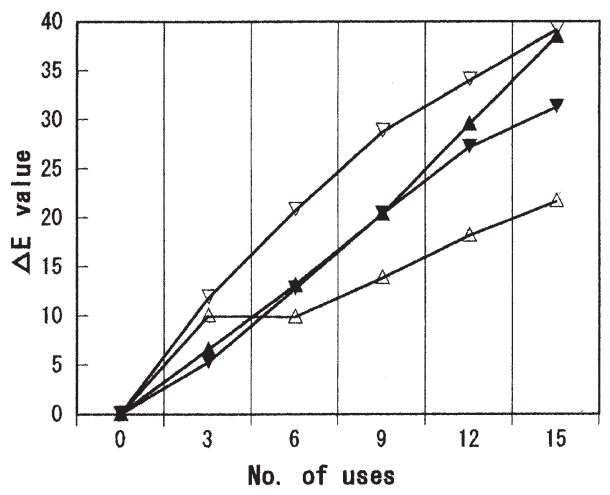

Fig. 5 Changes in Color Difference ( $\triangle \mathrm{E}$ value) of Sample Oils Listed in Table 2 by Aeration under Fluorescent Lamp.

$\boldsymbol{\Delta}$, TG-Toc; $\triangle$, TG-Toc/VC; $\boldsymbol{\nabla}$, DG-Toc; $\nabla$, DG-2 (DG-Toc/VC) . number of uses. COV and ANV tended to be slightly higher in DG-1 than in the other sample oils. AV increased slowly with the number of uses, but the amount of Toc did not influence AV. COV and ANV of the sample oils listed in Table 2 are shown in Fig. 7. COV and ANV increased rapidly with the number of uses as listed in Fig. 6, but the values of DG-Toc tended to be lower than those of the other sample oils. AV did not differ between TG oil containing Toc only and that containing both Toc and VC, whereas AV of DG-Toc increased gradually with the number of uses.

Table 5 shows the correlation coefficients of the parameters examined. There was no significant difference between the number of uses and oil absorption, dehydration rate, weight decrease or moisture content. However, dehydration rate, weight decrease and mois-
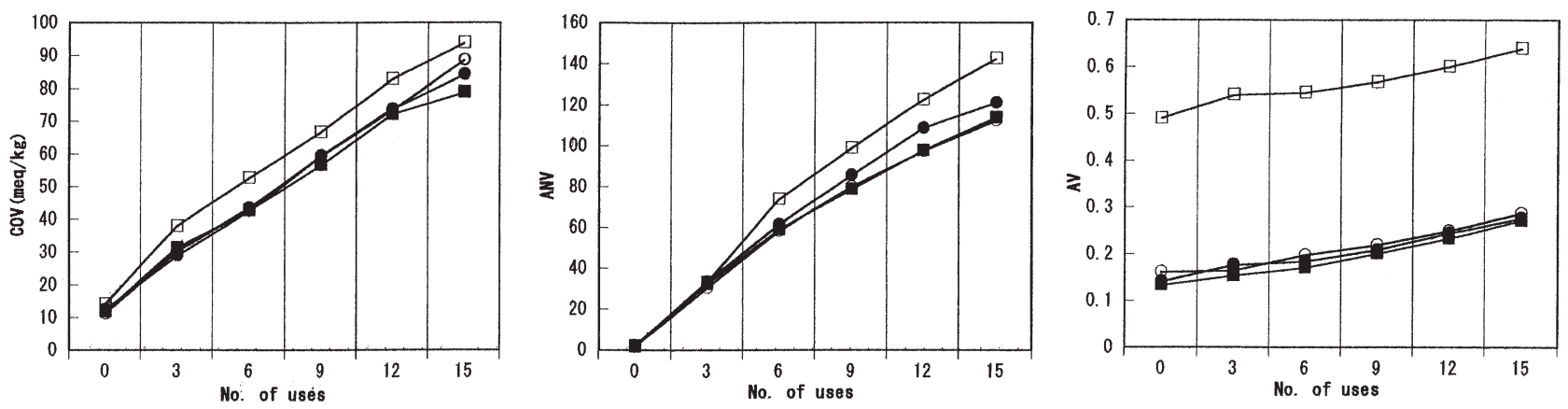

Fig. 6 Changes in Carbonyl (COV), p-Anisidine Value (ANV) and Acid Values (AV) of Sample Oils Listed in Table 1 by Number of Uses.

Left, COV; Middle, POV; Right, AV.

○, TG-1; ○, TG-2; $\square$, TG-H; $\square$, DG-1.
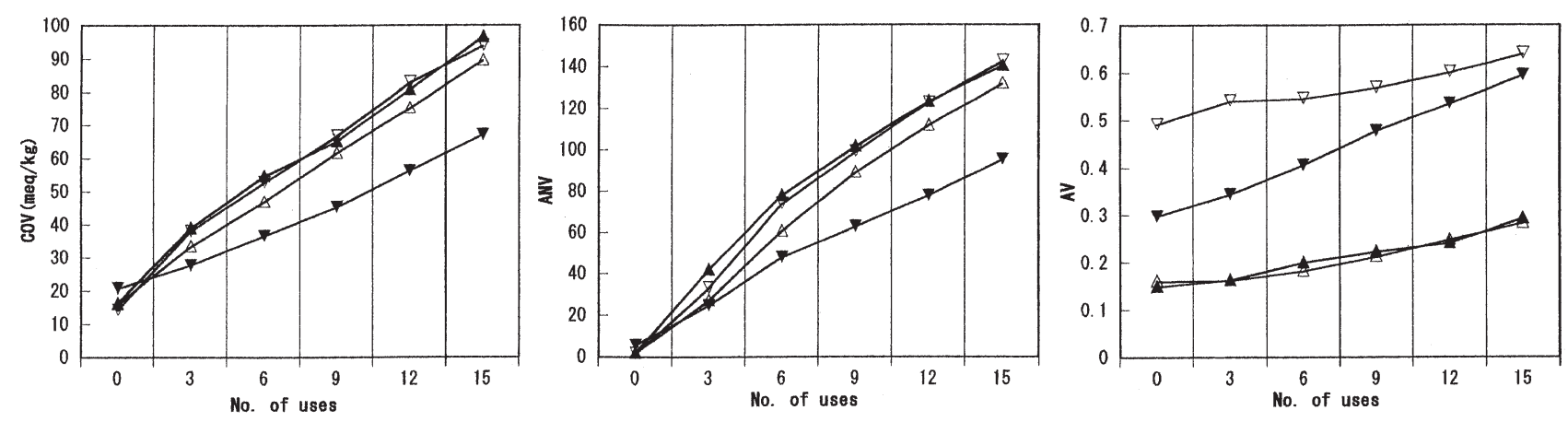

Fig. 7 Changes in Carbonyl (COV), p-Anisidine Value (ANV) and Acid Values (AV) of Sample Oils Listed in Table 2 by Number of Uses.

Left, COV; Middle, POV; Right, AV.

$\boldsymbol{\Delta}$, TG-Toc; $\triangle$, TG-Toc/VC; $\boldsymbol{\nabla}$, DG-Toc; $\nabla$, DG-2 (DG-Toc/VC) . 
Table 5 Correlation between the Parameters Examined.

\begin{tabular}{|c|c|c|c|c|c|c|c|c|}
\hline Parameter & $\begin{array}{l}\text { Number of } \\
\text { uses }\end{array}$ & $\begin{array}{l}\text { Oil } \\
\text { absorption }\end{array}$ & $\begin{array}{l}\text { Dehydra- } \\
\text { tion rate }\end{array}$ & $\begin{array}{l}\text { Weight } \\
\text { decrease }\end{array}$ & $\begin{array}{l}\text { Moisture } \\
\text { content }\end{array}$ & $\mathrm{COV}$ & ANV & AV \\
\hline Number of uses & 1.000 & & & & & & & \\
\hline Oil absorption & 0.165 & 1.000 & & & & & & \\
\hline Dehydration rate & -0.203 & $0.379^{*}$ & 1.000 & & & & & \\
\hline Weight decrease & -0.331 & $-0.520^{* *}$ & $0.593 * * *$ & 1.000 & & & & \\
\hline Moisture content & -0.135 & $-0.354^{*}$ & 0.033 & 0.338 & 1.000 & & & \\
\hline $\mathrm{COV}$ & $0.923 * * *$ & 0.062 & -0.250 & -0.285 & -0.173 & 1.000 & & \\
\hline ANV & $0.928 * * *$ & 0.052 & -0.257 & -0.282 & -0.142 & $0.982 * * *$ & 1.000 & \\
\hline $\mathrm{AV}$ & $0.340^{*}$ & -0.325 & -0.333 & -0.025 & 0.139 & 0.274 & 0.277 & 1.000 \\
\hline
\end{tabular}

ture content tended to increase with the number of uses. Oil absorption correlated positively with dehydration rate $(\mathrm{p}<0.05)$ and negatively with weight decrease $(\mathrm{p}<0.01)$ and moisture content $(\mathrm{p}<0.05)$. COV $(\mathrm{p}<0.001)$, ANV $(\mathrm{p}<0.001)$ and AV $(\mathrm{p}<0.05)$ correlated positively with the number of uses. COV, $\mathrm{ANV}$ and $\mathrm{AV}$, which are the indexes of chemical properties, showed no correlation with oil absorption, dehydration rate, weight decrease or moisture content, except that oil absorption and dehydration rate decreased when the amount of AV increased.

\section{Discussion}

Autoxidation of DG and TG oils at $50^{\circ} \mathrm{C}$ was almost the same as reported previously (7), and Toc and VC showed protective effects for oxidation. DG oil showed higher stability than TG oils in the presence of Toc and VC. As shown in Figs. 1 and 2, TG-H was oxidized more rapidly than TG-N due to differences in fatty acid composition (Table 1) (7). However, in the sample oils used in this study, the proportion of polyunsaturated fatty acids (PUFA) in DG oil was higher than that in TG oil. Therefore, these findings cannot explain the stability of DG oil.

With respect to TG oils, the $\Delta \mathrm{E}$ values increased with the amount of Toc added by aeration under fluorescent lamp at $40^{\circ} \mathrm{C}$. Toc seemed to be sensitive to oxidation by aeration. It is well known that the coloring of oil is caused by air (oxygen), temperature and light (12). Toc was oxidized rapidly by aeration, forming brown pigment (tocored). This oxidation might have caused the increase in the $\Delta \mathrm{E}$ values of $\mathrm{TG}$ oils containing Toc. The addition of $\mathrm{VC}$ to the sample oils containing Toc tended to be protective for oxidation of oils, and DG oil was found to be more stable than TG oil. Oxidized Toc was converted back to Toc by reacting with VC, which functioned as a reductant $(13,14)$. The structure of DG was more stable than that of TG, and hydrogen bond formed by the hydroxyl group in DG might be related to its stability $(15,16)$ because the viscosity of DG oil was higher than that of TG oil (7). PUFA were oxidized rapidly in air $(17,18)$ and $\mathrm{AV}$ did not change during incubation because no hydrolysis occurred. This finding may explain the difference in oxidation between the two oils. The $\Delta \mathrm{E}$ values were related to both $\mathrm{COV}$ and POV.

The thermal stability differed between oils that were autoxidized at $50^{\circ} \mathrm{C}$ and those that were autoxidized at $40^{\circ} \mathrm{C}$ by aeration. The $\Delta \mathrm{E}$ value of DG oil containing both Toc and $\mathrm{VC}$ was the highest among the sample oils, whereas the $\Delta \mathrm{E}$ value of $\mathrm{TG}$ oil containing both Toc and $\mathrm{VC}$ was the lowest. The $\Delta \mathrm{E}$ value of $\mathrm{DG}$ oil was higher than that of TG oil as reported previously $(7,15)$. This difference may be due to the difference in thermal resistance between the two lipids, TG and DG, and to the fact that Toc and $\mathrm{VC}$ deteriorate rapidly at temperatures around $180^{\circ} \mathrm{C}$. The COV and ANV of DG and TG oils with or without Toc did not differ markedly. Judging from the COV and ANV, DG oil containing Toc only was thermally and oxidatively more stable than the other sample oils. AV of the sample oils, particularly DG-Toc, increased with the number of uses because of the moisture content in the fried food. DG, 
an emulsifier, and PUFA were oxidatively more stable in an emulsion in the presence of an emulsifier $(17,18)$. The total proportions of $\mathrm{C} 18: 2$ and $\mathrm{C} 18: 3$ of TG-Toc and TG-Toc/VC, DG-Toc and DG-2 were $48.1 \%$, $47.0 \%$ and $54.8 \%$, respectively (Table 2 ). The amounts of C18:2 and C18:3 in DG oil decreased less than those in TG oil by frying (7). That the differences in fatty acid composition of oils may be related to oxidative stability, remains to be elucidated.

The dehydration rate, weight decrease and moisture content tended to decrease with the number of uses, which might be related to the oily or greasy taste of the fried food. The same frying experiment with TG oil (Nissin Oillio Co.) using four kinds of pans was carried out, and significant correlation between the number of uses and dehydration rate was observed $(\mathrm{r}=-0.375$, $\mathrm{p}<0.05)$ (Ohno, Y., unpublished data). This finding indicates that dehydration did not well occur inside the fried food with an increase in number of uses, which might cause the oily taste of the fried food. The oily taste seemed to be related not only to the oil content but also to the moisture content of the fried food. Therefore, a balance of between oil and moisture content in the fried food is important for maintaining the good taste of fried food.

\section{Conclusion}

DG oil containing Toc and VC showed the highest oxidative stability among the sample oils subjected to aeration under fluorescent lamp. The $\Delta \mathrm{E}$ value was related to both $\mathrm{COV}$ and POV. Toc seemed to stimulate the oxidation of TG oils in air, whereas the thermal stability differed between the oils that were autoxidized at $50^{\circ} \mathrm{C}$ and those that were autoxidized at $40^{\circ} \mathrm{C}$ by aeration. COV and ANV increased with the number of uses, although these values of DG oil containing Toc tended to be lower than those of the other sample oils. These results indicate that the distribution and composition of fatty acid, the difference in the structure of DG and TG, moisture, temperature and aeration under fluorescent lamp influence the oxidative stability of oils and that the stability of oils depends on these combined conditions. The dehydration rate, weight decrease and moisture content tended to decrease with the number of uses, which might be related to the oily or greasy taste of fried food.

\section{Acknowledgement}

The author would like to thank the Honen Co. and Nissin Oillio Co., Tokyo, for providing the sample oils.

\section{References}

1. H. WATANABE, K. ONIZAWA, H. TAGUCHI, M. KOBORI, H. CHIBA, S. NAITO, N. MATSUO, T. YASUKAWA, M. HATTORI and H. SHIMASAKI, Nutritional Characterization of Diacylglycerols in Rats, J. Jpn Oil Chem. Soc., Vol. 46, 301-307 (1997).

2. H. WATANABE, K. ONIZAWA, H. TAGUCHI, N. FUJIMORI, S. NAITO, N. GOTOH, T. YASUKAWA, M. HATTORI and H. SHIMASAKI, Effects of Diacylglycerols on Lipid Metabolism in Human, J. Jpn Oil Chem. Soc., Vol. 46, 309-314 (1997).

3. H. WATANABE, T. NAGAO, N. GOTOH, Y. FUKUSHIMA, K. ONIZAWA, H. TAGUCHI, T. OHMACHI, T. YASUKAWA, H. SHIMASAKI and H. ITAKURA, Long-Term Effects of Dietary Diacylglycerols on Body Fat Metabolism in Man, J. Jpn Oil Chem. Soc., Vol. 47, 369-376 (1998).

4. T. NAGAO, H. WATANABE, N. GOTOH, K. ONIZAWA, H. TAGUCHI, N. MATSUO, T. YASUKAWA, R. TSUSHIMA, H. SHIMASAKI and H. ITAKURA, Dietary Diacylglycerols Suppresses Accumulation of Body Fat Compared to Triacylglycerol in Men in a Double-Blind Controlled Trial, J. Nutr., Vol. 130, 792-797 (2000).

5. M. MURATA, T. IDE and K. HARA, Reciprocal Response to Dietary Diacylglycerol of Hepatic Enzymes of Fatty Acid Synthesis and Oxidation in the Rat, Br. J. Nutr., Vol. 77, 107-121 (1997).

6. K. YAMAMOTO, H. ASAKAWA, K. TOKUnAGA, H. WATANABE, N. MATSUO, I. TOKUMITSU and N. YAGI, Long-Term Ingestion of Dietary Diacylglycerol Lowers Serum Triacylglycerol in Type II Diabetic Patients with Hypertriglyceridemia, J. Nutr., Vol. 131, 3204-3207 (2001).

7. Y. OHNO, Deep-frying Oil Properties of Diacylglycerol-rich Cooking Oil, J. Oleo Sci., Vol. 51, 275-279 (2002).

8. Standard Methods for Analysis of Fats and Oils, 4.2.1-71, (Jpn. Oil Chem. Soc., ed.), Tokyo (1981).

9. Standard Methods for Analysis of Fats and Oils, 2.4.12-86, (Jpn. Oil Chem. Soc., ed.), Tokyo (1981).

10. Standard Methods for Analysis of Fats and Oils, 2.4.26-81 (Jpn. Oil Chem. Soc., ed), Tokyo (1981).

11. T. CHIBA, M. TAKIZAWA and K. FUJimOTO, A Simple Method for Estimating Carbonyl Content in Peroxide-Containg Oils, J. Am. Oil Chem. Soc., Vol. 66, 1588-1592 (1989).

12. S. OTA, Edible Oils, Gakkenshoin, Tokyo, pp. $98-99$ (1974).

13. J.E. PACKER, T.F. SLATER and R.L.WILLSON, Direct Observation of a Free Radical Interaction between Vitamin $\mathrm{E}$ and Vitamin C, Nature, Vol. 278, 737-738 (1979).

14. E. NIKI, Inhibition of Oxidation of Lipids by Antioxidant Vitamins, Jpn. J. Nutr. Diet., Vol. 51, 115-121 (1993). 
15. K. NAKATSUGAWA, K. OHASHI and A. SHIMADA, Comparison of Oxidative Stability of Diacylglycerol and Triacylglycerol, Nippon Shokuhin Kagaku Kougaku Kaishi, Vol. 48, 429436 (2001)

16. T. MIYAZAWA (Jpn. Oil Chem. Soc., ed.), The Handobook of Oil Chemistry, 4th ed., Maruzen K.K., Tokyo, pp. 183-190 (2001).
17. K. MIYASHITA, M. HIRANO, E. NARA and T. OTA, Oxidative Stability of Triglycerides from Orbital Fat of Tuna and Soybean Oil in an Emulsion, Fisheries Sci., Vol. 61, 273-275 (1995).

18. K. MIYASHITA, Oxidative Stability of Polyunsaturated Fatty Acids in an Aqueous Dispersion, Nippon Shokuhin Kagaku Kougaku Kaishi, Vol. 43, 1079-1085 (1996). 